\title{
Atomistic modeling of crystal structure of
}

${ }^{a}$ Theoretical Chemistry, P.O.B. 124, Lund University, Lund 22100, Sweden

$\dagger$ Corresponding author: Tel: +46-46-2223110. E-mail: valera.veryazov@teokem.lu.se (V. Veryazov)

${ }^{\mathrm{b}}$ BASF Construction Solutions GmbH, Advanced Materials \& Systems Research, Albert Frank Straße 32, 83304 Trostberg, Germany.

${ }^{\mathrm{c}}$ Laboratoire Interdisciplinaire Carnot de Bourgogne, UMR 6303 CNRS-Université de Bourgogne, BP 47870 F-21078 Dijon Cedex, France

The atomic structure of calcium-silicate-hydrate $\left(\mathrm{C}_{1,67-} \mathrm{S}-\mathrm{H}_{\mathrm{x}}\right)$ has been investigated by theoretical methods in order to establish a better insight into its structure. Three models for CS-H all derived from tobermorite are proposed and a large number of structures were created within each model by making a random distribution of silica oligomers of different size within each structure. These structures were subjected to structural relaxation by geometry optimization and molecular dynamics steps. That resulted in a set of energies within each model. Despite an energy distribution between individual structures within each model, 
significant energy differences are observed between the three models. The C-S-H model related to the lowest energy is considered as the most probable. It turns out to be characterized by the distribution of dimeric and pentameric silicate and the absence of monomers. This model has mass density which is the closest to the experimental one.

Keywords: C-S-H structure, atomistic simulation, ReaxFF

\section{Introduction}

Calcium-silicate-hydrate (C-S-H) is the most important phase in hydrated Portland cement, the most widespread construction material. It emerges as a nanostructured gel, from the mixture of water and cement powder and it is responsible for the hardening of concrete [1]. On the nanoscale, bulk C-S-H is composed of particles of tens nanometers or less in all directions [2-6]. Despite the enormous importance of this material and long history of usage, the atomic structure of C-S-H precipitating during the cement hydration is still under discussion [6-11]. The reason is due to a lack of decisive experimental technique. This experimental difficulty originates from the nanometer size of the particles and from a variable stoichiometry along the cement hydration. The principal technique usually used for crystal structure determination is X-ray diffraction but in this case it is of little help due to the poorlydefined diffraction patterns obtained. Most of the experimental information on the C-S-H structure came from solid state NMR [12-21], X-ray powder diffraction [6, 18, 22-25] and transmission electron microscopy $[26,27]$. C-S-H is determined to be a compound of general formula $\mathrm{C}_{\mathrm{x}} \mathrm{S}_{\mathrm{y}} \mathrm{H}_{\mathrm{z}}$ where letters $\mathrm{C}, \mathrm{S}$, and $\mathrm{H}$ are used as symbol for oxides $\mathrm{CaO}, \mathrm{SiO}_{2}$ and $\mathrm{H}_{2} \mathrm{O}$. The calcium to silicon ratio $(\mathrm{C} / \mathrm{S})$ in $\mathrm{C}-\mathrm{S}-\mathrm{H}$ can vary in wide range from about 0.8 to 2 during 
cement hydration [26-28], the lowest value being only reached by addition of silica rich supplementary cementitious materials such as silica fume or fly ash. It is now well admitted that the basic atomic structure of $\mathrm{C}-\mathrm{S}-\mathrm{H}$ particles of the lowest $\mathrm{C} / \mathrm{S}$ ratios is close to the structure of a natural calcium silicate hydrate: tobermorite $[6,8,10,11,19,22,29,30]$. However, the tobermorite $\mathrm{C} / \mathrm{S}$ ratio is close to only 0.8 and the typical $\mathrm{C} / \mathrm{S}$ ratio in hydrated cement paste is 1.7 . Until now, there is no consensus on the exact crystal structure of C-S-H for the highest $\mathrm{C} / \mathrm{S}$ ratios. To reach such high ratios, it was proposed that $\mathrm{C}-\mathrm{S}-\mathrm{H}$ in cement could be a mix of tobermorite and jennite (another natural calcium silicate hydrate with $\mathrm{C} / \mathrm{S}=$ 1.5) [10]. In fact, synthetic C-S-H with $\mathrm{C} / \mathrm{S}$ ratio as high as 1.5 never shows XRD patterns characteristic of jennite and keeps a diffraction pattern compatible with a tobermorite-like structure $[6,18,22-24]$. The question is still open for higher $\mathrm{C} / \mathrm{S}$ ratios $(>1.5)$ such as encountered in cement paste because of the difficulty to synthesize this pure phase alone and therefore to make reliable analyses. However, few attempts based on the full hydration of tricalcium silicate or dicalcium silicate suggest that the tobermorite-like structure is still preserved $[6,31]$ as proposed in the early 1950 s by Grudemo. The community appears to be developing a consensus that C-S-H keeps a tobermorite-like structure over the whole C/S ratio range. Therefore, several models based on tobermorite have been proposed along the last decades $[6,11,23,24,32-34]$ to describe the structure of C-S-H at C/S ratios relevant of cement pastes. The structure of C-S-H with low content of Ca has been also studied [35-36]. Layers in tobermorite are composed of calcium atoms (intra-layers) that are sandwiched by parallel silicate chains (Figure 1). The silicate chains present a Dreieketten structure, i.e., a chain of dimeric silicates terahedra, linked by a bridging silicate. Two oxygen atoms of the dimeric silicate coordinate the intralayer calcium ions, one is shared with the second silicate of the dimer and the last is shared with the bridging tetrahedron. The space between layers 
1 (interlayer) is filled with calcium atoms coordinated by water molecules and the oxygen atoms of the bridging tetrahedrons. There are several modifications of tobermorite that differ in the level of hydration and degree of cross-linking of the silicate chains of two adjacent layers, also, these forms have different interlayer separations. They are named according to that separation: $9 \AA, 11 \AA$, and $14 \AA$ tobermorites [23, 24, 34,37-38]. In $9 \AA$ and anomalous $11 \AA$ tobermorites, two parallel silicate chains from two different layers are bridged by $\mathrm{Q}_{3}$ silicate type forming a double-chain silicate structure (these silicon atoms are marked with blue color in Figure 1)[8, 34, 39, 40]. In normal $11 \AA$ and $14 \AA$ tobermorites, the number of $\mathrm{Q}_{3}$ drastically decreases leading to a single-chain silicate structure in which all silicate dimers chains are bridged with third silicate tetrahedrons forming a repeating unit of three tetrahedrons (Dreierketten) within infinite chains.
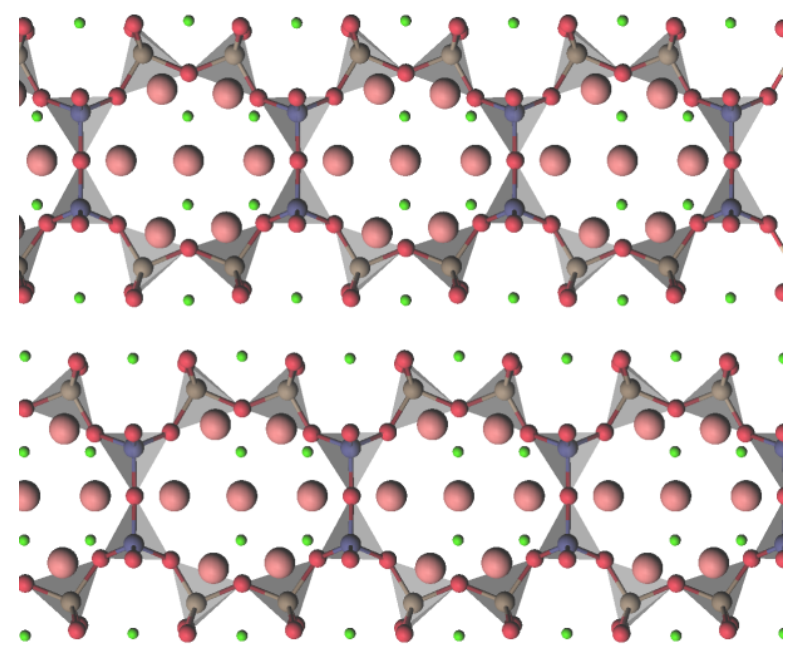

Figure 1: Initial structure, based on ideal tobermorite structure used for building models. Silicon atoms of the bridging tetrahedrons $\left(\mathrm{Q}_{3}\right)$ are represented in blue. Here the silicate chains of adjacent layers are also The structure of C-S-H is believed to be composed of intra-layers and interlayers just like in $14 \AA$ tobermorite. Then, the exercise to make C-S-H from the tobermorite structure consists in 
an increase of the $\mathrm{C} / \mathrm{S}$ ratio of this latter. Two mechanisms are well identified. The first is the progressive elimination of the bridging tetrahedrons which creates $\mathrm{SiO}_{2}$ vacancies resulting in silicate oligomers instead of infinite chains. C-S-H with the lowest $\mathrm{C} / \mathrm{S}$ shows a strong ${ }^{29} \mathrm{Si}$ NMR signal originating from Si connected to two neighbors Si by Si-O-Si bonds $\left(\mathrm{Q}_{2}\right)$ and a weak signal from the threefold-connected $\mathrm{Si}\left(\mathrm{Q}_{3}\right)[8,19-21]$. This is consistent with the model where $\mathrm{SiO}_{2}$ is in the form of infinite chains that are seldom interlinked. As $\mathrm{C} / \mathrm{S}$ ratio increases, Q3 weakens and disappears and $\mathrm{Q}_{1}$, corresponding to end of shorter oligomeric units appears. At about $\mathrm{C} / \mathrm{S}=1$, the average chain is pentamer, and at $\mathrm{C} / \mathrm{S}=1.5$ (close to the common $\mathrm{C}-\mathrm{S}$ $\mathrm{H}$ composition), the strongest signal comes from the $\mathrm{Q}_{1}$ species since most of the silicate units

\section{are dimers $[8,19,20]$. This observation is in accordance with theoretical findings showing} that the most stable silicate oligomers are dimers, pentamers and octamers [41]. The second mechanism is the progressive replacement of protons by calcium ions in interlayers. These protons are initially charge-balanced by the bridging tetrahedrons that only have two uncoordinated oxygen atoms. However, these two mechanisms are not sufficient to account for $\mathrm{C} / \mathrm{S}$ ratios higher than 1.5 . As a matter of fact, the elimination of all bridging tetrahedrons and the replacement of all protons by calcium ions only result in a $\mathrm{C} / \mathrm{S}$ ratio of 1.5 . It is however experimentally observed that for this stoichiometry, few pentamers still exist; also, a third mechanism is needed to further increase the calcium to silicon ratio. Two possibilities have been proposed. The first one consists in removing a part of the silicates coordinating the intralayer calcium ions locally creating jennite like structures [8]. In the second one, extra calcium ions charge balanced by hydroxide ions are inserted in the interlayer [6, 31]. Both processes lead to the formation of $\mathrm{Ca}-\mathrm{OH}$ bonds which are identified by NMR and IR spectroscopies [21, 42-44]. At a constant crystal cell volume, the first way tends to decrease the density, the second way to increase it. The density of C-S-H significantly varies with the water content (from 2.5 to $2.9 \mathrm{~g} / \mathrm{cm}^{3}$ ) and therefore experimental values obtained are strongly 
depending on the technique used involving a drying step or not [45] . Recently, small angle neutron scattering measurements determined the density of C-S-H in cement to be $2.6 \mathrm{~g} / \mathrm{cm}^{3}$ [46]. A density value of about $2.7 \mathrm{~g} / \mathrm{cm}^{3}$ for C-S-H in hydrated cement paste was also deduced from proton NMR relaxometry and mass balance calculation [47]. This C-S-H density is definitely greater than the density corresponding to $11 \AA$ tobermorite $\left(2.48 \mathrm{~g} / \mathrm{cm}^{3}\right)$ and also greater than the density of jennite $\left(2.33 \mathrm{~g} / \mathrm{cm}^{3}\right)$.

To the best of our knowledge, only one of the above mechanisms was used as a basis for molecular modeling. Indeed, Pellenq at al. [33] developed a model for C-S-H used in several theoretical researches [48-50]. The features of Pellenq's model are the following: the C/S ratio is very close to the average $\mathrm{C} / \mathrm{S}$ in $\mathrm{C}-\mathrm{S}-\mathrm{H}$ (1.65). This high $\mathrm{C} / \mathrm{S}$ is mainly achieved according to the second process described above, i.e., by randomly removing silicate tetrahedrons. It units $\left(\mathrm{Q}_{0}\right)$. The interlayer separation after optimization is of about 11.3-11.9 $\AA$. This model can correctly describe several experimental data: radial distribution functions of $\mathrm{Ca}, \mathrm{CaO}$ and $\mathrm{SiO}$, and IR spectra. The Pellenq's model also received critics because some of the Ca-O distances are unrealistic [51] and as it failed to reproduce the experimental density of C-S-H [52]. Moreover motivated by the presence of protonated silicate monomers in ${ }^{29} \mathrm{Si}$ NMR spectra of hydrated tricalcium silicate pastes [53], monomeric silicate units were introduced in that model. However, ascribing these monomeric silicates to C-S-H is questionable because such a signal is never seen in spectra of pure C-S-H samples even at high C/S. Another explanation could be the presence of possible local rests of the nesosilicate $\mathrm{C}_{3} \mathrm{~S}$ used as reactant which is superficially hydroxylated in contact with water [13].

The determination of the exact C-S-H structure remains an important issue because of its importance in other meso- and macroscopic models [54, 55]. The problem is a lack of long- 
range order in C-S-H which makes challenging the determination of the crystal structure by usual techniques. Theoretical calculations of the energy of possible C-S-H structures can help to determine the most stable one. Nevertheless, an attempt to construct all possible atomic CS-H structures, satisfying the experimental composition, leads to an almost infinite number of structures. These latter will show the same or similar short range order but will differ at the long range (position of ions and independent blocks, e.g. water molecules). Different rules

\section{The construction of structural models}

The basic approach in constructing realistic structures of C-S-H is to use the similar known structure of tobermorite and modify it in order to make it consistent with the correct chemical composition of C-S-H. According to theoretical modeling NMR spectra in C-S-H [35], jennite based models can be excluded from the consideration. From a practical point of view, the monoclinic tobermorite $11 \AA \AA$ structure (space group B11m) suggested by Merlino et al. is our starting point [40]. Models based on the tobermorite structure, suggested by Hamid [30] will require larger unit cells. However, the main structural motives will remain the same. The notation published by Merlino (see Table 1 and Figure 2) will be used and referred to the notation of the unit cell therein. However, in this structure, the silicate chains of two layers are 
cross-linked, O5 is shared by two different layers. Using this model for C-S-H means that great care must be taken with the suppression of all these bridges since they do not exist in CS-H. The reported structure of tobermorite contains partially occupied Wyckoff positions for $\mathrm{Ca} 2$ atoms. In addition $\mathrm{SiO}_{2}$ fragments in the structure have to be randomly removed. For an atomistic modeling of such a system, one has to use the large unit cell approach: unit cell vectors are multiplied in order to achieve integer occupation numbers for all atoms. In order to maintain flexibility in keeping integer occupation numbers after following modifications of the structure, a supercell containing $16(4 \times 4 \times 1)$ original tobermorite unit cells has been chosen.

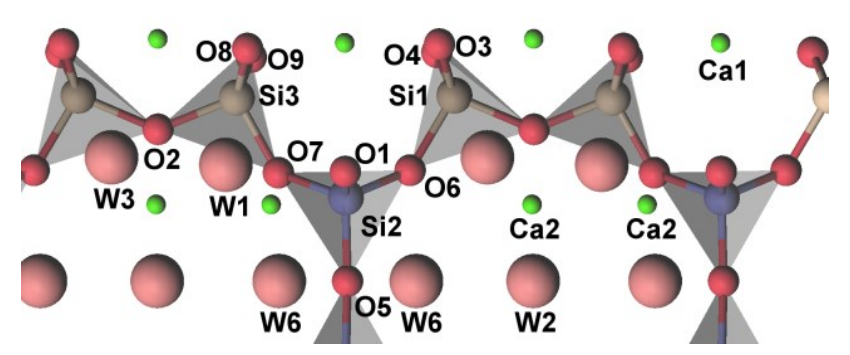

Figure 2: Atom labeling in the models 1,2 and 3. W stands for a water molecule.

First of all the $\mathrm{C} / \mathrm{S}$ ratio has to be corrected. It is possible to achieve this by the addition of calcium ions and/or the removing of silicate tetrahedrons. In particular, the removing of silicon atoms can be performed in different ways, i.e., either by controlling the size and the type of Si-O-Si fragment (for example a removed tetramer could be constituted of one dimer and two bridging tetrahedrons or one dimer one bridging tetrahedron and one monomer part of another dimer as well) either in a totally random way (as it was proposed by Pellenq [33]). Based on these possibilities, three different models built according to the way for removing the silicate units are proposed: 
- Model 1 is built by both adding calcium charge balanced by hydroxide ions and removing only bridging silicate tetrahedrons in a random process.

- Model 2 is a model in which dimers are also removed.

- Model 3 is a model where silicate units are randomly removed.

Each model has previously been discussed and examined in the literature $[6,8,33]$. All models have in common that the tobermorite structure is modified so that the calcium to silicon ratio is increased to 1.68 .

- Model 4 is taken from Pellenq et al. [33].

Table 1: Silicon and calcium atoms in the unit cell of normal tobermorite [40], *has occupancy of $1 / 4$. Unit cell dimensions are: $a=6.735 \AA, b=7.425 \AA, c=27.987 \AA, \gamma=123.25^{\circ}$.

\begin{tabular}{|l|l|l|l|}
\hline & \multicolumn{1}{|c|}{$\mathrm{x}$} & \multicolumn{1}{|c|}{$\mathrm{y}$} & \multicolumn{1}{|c|}{$\mathrm{z}$} \\
\hline $\mathrm{Si} 1$ & 0.757 & 0.388 & 0.157 \\
$\mathrm{Si} 2$ & 0.915 & 0.756 & 0.071 \\
\hline Si3 & 0.758 & 0.967 & 0.159 \\
$\mathrm{Ca} 1$ & 0.263 & 0.431 & 0.207 \\
\hline Ca2 & 0.559 & 0.078 & 0.044 \\
\hline Ca3 & 0.752 & 0.923 & 0.295 \\
\hline O1 & 0.754 & 0.499 & 0.095 \\
\hline O2 & 0.772 & 0.185 & 0.133 \\
\hline O3 & 0.992 & 0.537 & 0.097 \\
\hline O4 & 0.523 & 0.312 & 0.195 \\
\hline
\end{tabular}




\begin{tabular}{|l|l|l|l|}
\hline O5 & 0.898 & 0.752 & 0.000 \\
\hline O6 & 0.197 & 0.896 & 0.095 \\
\hline O7 & 0.752 & 0.853 & 0.097 \\
\hline O8 & 0.524 & 0.807 & 0.196 \\
\hline O9 & 0.984 & 0.045 & 0.200 \\
\hline W6 & 0.237 & 0.416 & 0.097 \\
\hline W1 & 0.420 & 0.240 & -0.020 \\
W2 & 0.922 & 0.250 & 0.000 \\
\hline W3 & 0.400 & 0.760 & -0.019 \\
\hline
\end{tabular}

As previously mentioned, the procedures (due to random removal of atoms) generate a huge number of different crystals. Moreover a part of them do not necessarily agree with some experimental evidences. In order to fix this problem, some selection rules dictated from these experimental observations have been imposed. The very convincing data from the ${ }^{29} \mathrm{Si} \mathrm{NMR}$ studies $[3,6]$ have shown that in pure $\mathrm{C}-\mathrm{S}-\mathrm{H}$ at high $\mathrm{C} / \mathrm{S}$ bridging tertiary silica groups $\left(\mathrm{Q}_{3}\right)$ do not exist. Hence, likely C-S-H structures cannot tolerate any appreciable number of such bridges. Similarly, structures that contain monomeric silicate are not supported by ${ }^{29} \mathrm{Si}$ NMR studies $[3,6]$ and are eliminated except in model 3. The ratio, $\mathrm{Q}_{2} / \mathrm{Q}_{1}(>0.2)$ also respects the experimental value determined from ${ }^{29} \mathrm{Si}$ NMR. The crystal structures, obtained from the Xray analysis contain the positions of water oxygen but no information of the orientation of water molecules. The positions of water molecules were shifted in order to get the optimal intermolecular distance, and oriented in such a way that each water molecule makes at least one hydrogen bond with its neighbor. The orientation of the water molecules was determined 
1 by random rotations around the center of mass of each molecule providing that hydrogen

2 atoms in water molecules are well separated from other atoms.

\subsection{Models}

\subsubsection{Model 1}

The procedure for model 1 is:

- Initial structure is taken from the tobermorite structure (unit cell $4 \times 4 \times 1$, see Table 1 ) and $\mathrm{Ca} 2$ positions were duplicated to achieve the composition: $\mathrm{Ca}_{256} \mathrm{Si}_{192} \mathrm{O}_{576} \cdot 224 \mathrm{H}_{2} \mathrm{O}$.

- $56 \mathrm{Si} 2$ atoms are randomly removed leaving a composition of $\mathrm{Ca}_{256} \mathrm{Si}_{136} \mathrm{O}_{576} \cdot 224 \mathrm{H}_{2} \mathrm{O}$

11 taking care that no interlayer bridges are left.

- Hydrogen atoms are added to the $\mathrm{O} 5$ and $\mathrm{O} 6$ where $\mathrm{Si} 2$ has been removed. One hydrogen atom is added to either $\mathrm{O} 5$ or $\mathrm{O} 6$ attached to remaining $\mathrm{Si} 2$. The composition after the hydrogen addition is: $\mathrm{Ca}_{256} \mathrm{Si}_{136} \mathrm{O}_{504} \mathrm{H}_{8}(\mathrm{OH}){ }_{82} \cdot 254 \mathrm{H}_{2} \mathrm{O}$.

- $27 \mathrm{Ca} 2$ atoms and their duplicates $(\mathrm{Ca} 4)$ are removed from random positions, resulting in composition: $\mathrm{Ca}_{229} \mathrm{Si}_{136} \mathrm{O}_{560} \mathrm{H}_{64}(\mathrm{OH}){ }_{82} 254 \mathrm{H}_{2} \mathrm{O}$.

The model (Figure 3A) is based on a calcium doped structure where each position of water coordinated calcium has been duplicated. Compared to tobermorite this model is composed of dimers and pentamers of silicon oxides with no interlayer bridging silicate Si2. The structures are generated by randomly removing 56 out of the 64 bridging tetrahedrons in the super cell, satisfying the experimental $\mathrm{Q}_{1} / \mathrm{Q}_{2}$ ratio, without any interlayer bridges. For some silicon atoms removed, one hydrogen atom is added to flank the oxygen atoms in the tetrahedron. 
1 Using the nomenclature of Merlino et al. [40] this corresponds to O5 and O6. To achieve 2 appropriate ratio of calcium and silicon atoms, 27 calcium atoms out of 128 , situated in the

3 interlayer were randomly removed. This generates structures with a slight excess of positive 4 charge. The charge is balanced by removing randomly chosen protons.

\subsubsection{Model 2}

- Initial composition is the same as in model 1 (tobermorite structure): $\mathrm{Ca}_{192} \mathrm{Si}_{192} \mathrm{O}_{576} \cdot 192$ $\mathrm{H}_{2} \mathrm{O}$.

- 11 chains constituted of $\mathrm{Si} 2, \mathrm{O} 7, \mathrm{Si} 3, \mathrm{O} 2, \mathrm{Si} 1, \mathrm{O} 1, \mathrm{Si} 2$, atoms are removed. The composition 11 becomes: $\mathrm{Ca}_{192} \mathrm{Si}_{148} \mathrm{O}_{543} \cdot 192 \mathrm{H}_{2} \mathrm{O}$.

- 34 additional $\mathrm{Si} 2$ are randomly removed resulting in: $\mathrm{Ca}_{192} \mathrm{Si}_{114} \mathrm{O}_{543} \cdot 192 \mathrm{H}_{2} \mathrm{O}$.

- Hydrogen atoms are added to the $\mathrm{O} 3$ and $\mathrm{O} 4$ that have been previously connected to $\mathrm{Si} 1$ or $\mathrm{Si3}$.

- Uncoordinated O6 are removed and hydrogen atoms are added to the unsaturated oxygen atoms such that electro-neutrality is achieved. The final average composition is: $\mathrm{Ca}_{192} \mathrm{Si}_{114} \mathrm{O}_{393} \mathrm{H}_{211}(\mathrm{OH}){ }_{263} 22 \mathrm{H}_{2} \mathrm{O}$.

Model 2 (Figure 3B) is also generated as a distribution of dimers and pentamers satisfying the experimental $\mathrm{Q}_{1} / \mathrm{Q}_{2}$ ratio. The procedure however differs from the previous situation in the sense that the structures are generated by removing silicate tetramers. Eleven of these tetramers, $\mathrm{Si} 2-\mathrm{O} 7-\mathrm{Si} 3-\mathrm{O} 2-\mathrm{Si} 1-\mathrm{O} 1-\mathrm{Si}$, were removed. To achieve the desired $\mathrm{C} / \mathrm{S}$ ratio, further $34 \mathrm{Si} 2$ atoms were removed. Hydrogen atoms were added to the $\mathrm{O} 3$ and $\mathrm{O} 4$ oxygen atoms, next to the removed tetramers. Hydrogen atoms were also added to the remaining O5 
and $\mathrm{O} 6$ oxygen atoms of $\mathrm{Si} 2$ silicon atoms. Additional hydrogen atoms were distributed over the deprotonated silanols to achieve electro-neutrality. These structures also satisfy the experimental $\mathrm{Q}_{1} / \mathrm{Q}_{2}$ ratio, without any interlayer bridges.

\subsubsection{Model 3 (and 4).}

- The initial composition is the same: $\mathrm{Ca}_{192} \mathrm{Si}_{192} \mathrm{O}_{576} \cdot 192 \mathrm{H}_{2} \mathrm{O}$.

- The $\mathrm{Si} 2$ bridges are broken by removing 32 randomly selected Si2 atoms. Another 46 randomly chosen silicon atoms are removed resulting in the formula: $\mathrm{Ca}_{192} \mathrm{Si}_{114} \mathrm{O}_{576} \cdot 192 \mathrm{H}_{2} \mathrm{O}$.

- All unsatisfied valencies on the O3, O4 and $\mathrm{O} 5$ oxygen atoms, which resulted from the removal of the silicon atoms are satisfied by adding hydrogen atoms. Many of the O5 atoms are converted to water in this step.

- Charge balance is restored by removing some of the uncoordinated oxygen atoms.

- Water molecules are removed if they were too close to other atoms.

- That resulted in the average final composition: $\mathrm{Ca}_{192} \mathrm{Si}_{114} \mathrm{O}_{386} \mathrm{H}_{22}(\mathrm{OH}){ }_{88} \cdot 151 \mathrm{H}_{2} \mathrm{O}$ The structure published by Pellenq et al.[33] shows the same feature as this model 3, but we will labeled it "Model 4" for the sake of simplicity in the discussion. This structure is also built on tobermorite but by randomly removing silicon oxide fragments. Since the individual structures were created by randomly removing silicon oxide units, without referring to their positions in the crystal lattice, the composition of model 3 is much more inhomogeneous than models 1 and 2. With this model 3, large amount of $\mathrm{Q}_{0}$ silicate (monomers) can arise in the resulting structures which would not fit with any NMR data. structures which contain more 
than $12 \%$ of silica monomers were excluded; this amount corresponds to the one, proposed by Pellenq in his model.

For each H/S ratio in models 1-3 about hundred structures were generated which makes more than a thousand structures in total. During the random process of construction the amount of water was not controlled. In order to build structures with different water content, water molecules were randomly removed. To summarize, each model contains structures with identical $\mathrm{C} / \mathrm{S}$ ratio, but different $\mathrm{H} / \mathrm{S}$ ratio.

A
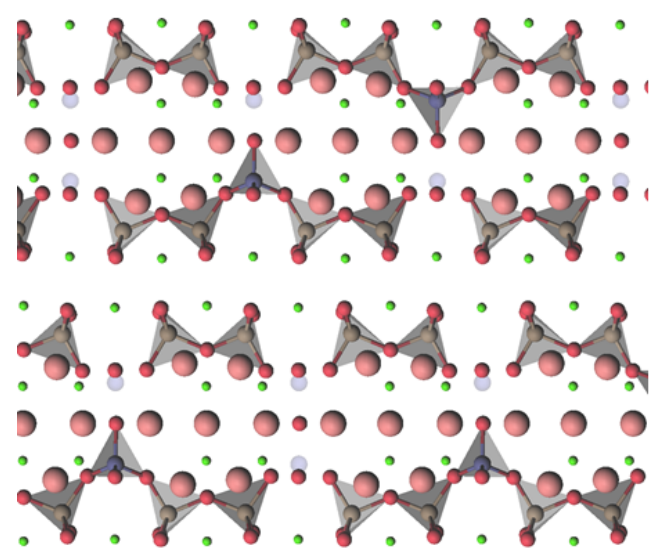

\section{C}
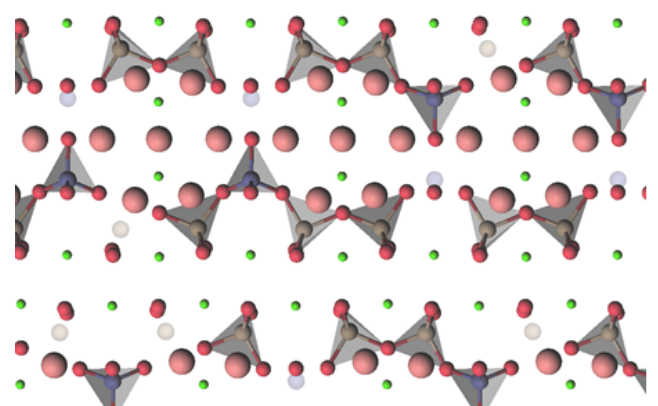

D 0600080000000

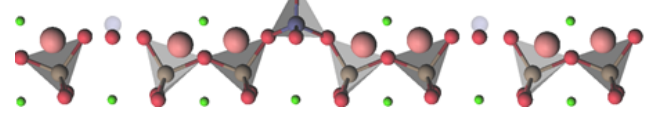
oligomers of different length are observed.

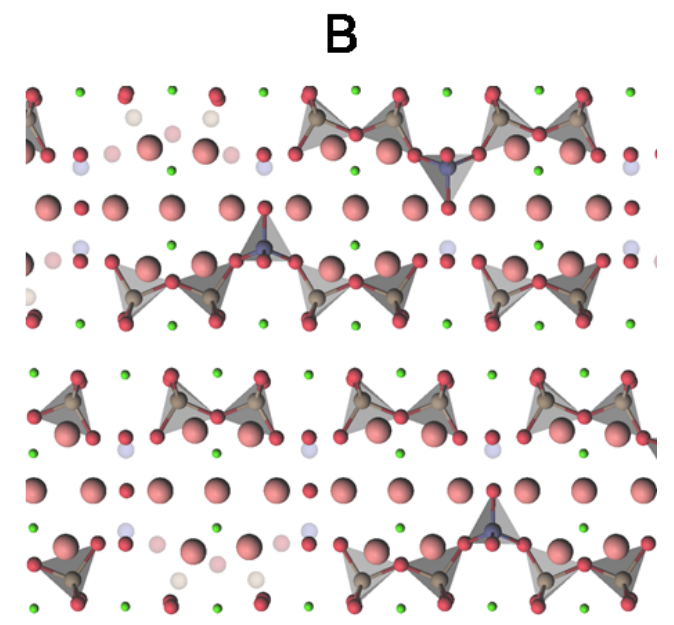

Figure 3: Typical structures corresponding to the three models for $\mathrm{C}_{1,67}-\mathrm{S}-\mathrm{H}_{\mathrm{x}}$ : A: model 1; B: model 2; C:

model 3. Atoms removed from the original tobermorite structure are shown as translucent. See figure 2 for atom labeling. In model 1, silicates chains are composed of silicate pentamers and dimers, in model 2 it is the same but larger holes are also observed due to the removal of large silicate units and in model 3 


\section{Simulation details}

Performing calculations of all generated structure samples is time consuming and meaningless task: random creation of defects in the tobermorite structure generates very large amount of possible crystal structures. For instance, for model 1, corresponding to $4 \times 4 \times 1$ tobermorite unit cell, it is possible to create $\sim 10^{37}$ permutations for $\mathrm{Ca}$ and Si defects! Instead a subset of structures was randomly selected and relaxation calculations for this subset were performed. If structures within the subset are similar in terms of total energy and structural properties (such as unit cell parameters) to each other the result can be generalized to all structures of the considered models and it can be assumed that any crystal structure of the model will have similar energy and structural properties.

In those simulations atom coordinates are relaxed as well as unit cell parameters whereas alpha and beta angles were kept equal to $90^{\circ}$. Initial structures are artificial and might contain unrealistic distances between atoms. The direct optimization of such structures usually leads to unrealistic results. Rather, relaxation was performed in two steps. First silicon atoms were constrained and the rest was relaxed and the relaxation on all atoms was performed during a second step. This strategy allows preserving structural elements defined in each individual model with an optimization of structures in the same time. Low temperature molecular dynamics (MD) simulation was used in order to relax unit cell parameters with preserving structural elements. The relaxation was done by the optimization of the generated structures, followed by molecular dynamics (MD) simulation at low temperature $(0.1 \mathrm{~K}, 20 \mathrm{fs})$. Nose- 
Hoover thermostat and barostat were applied in the MD simulations. Initial velocities in the MD simulations are initiated with different random numbers in each sample. The structure optimization and low temperature MD simulation $(0.1 \mathrm{~K}, 50 \mathrm{fs})$ were repeated without restriction (frozen atoms). The structure was finally optimized again. All calculations were done with the lammps program package [56] using the ReaxFF force field [57]. The parameters set used in this work were already used in MD simulations of C-S-H [58] and were optimized for Si-O-H [59] and Ca-O-H [58] systems. The C-S-H bulk densities are estimated on relaxed structures. The results were also justified by calculating total energies of structures after applying room temperature $(300 \mathrm{~K})$ conditions. Although the absolute values for total energies were changed, the change was almost constant for all structures with a typical variation in energy differences less than $0.05 \mathrm{eV}$.

\section{Results}

Although all three models were generated from the same crystal structure of tobermorite, the algorithms do not guarantee the same stoichiometry which complicates the direct comparison of energies between the models. Indeed, models 2 and 3 are the result of removing a greater number of silicon atoms than model 1 . Since the ratio of calcium to silicon atoms is kept constant in all models, model 1 yields an increased number of calcium atoms too. Therefore all energies in model 2 and 3 were scaled according to the number of silicon atoms in model 1. Those rescaled energies are still not comparable because individual structures can contain different amount of water molecules. To compare the energies we selected a structure with minimal amount of water molecules and considered all other structures as formally containing an excess of water. The total energy of the system can be approximately presented as the 
1 energy of the basic structure plus the energy of extra water molecules (in a form of solvated

2 water). Thus we compensated the total energy of the system by subtracting the energy of the 3 necessary amount of solvated water molecules. The relative energies for model 1-4 in function of the H/S ratio are shown in Figure 4. The $\mathrm{H} / \mathrm{S}$ ratio range covered by the different models is determined by their structure: in model 2 which contains large amount of hydroxyl groups, H/S value below 1.9 cannot be obtained by the removal of water molecules, and model 3 does not have enough space to accept more water molecules. For all $\mathrm{H} / \mathrm{S}$ ratios, the $\mathrm{C}-\mathrm{S}-\mathrm{H}$ structures related to model 1 exhibit the lowest energy. Thus, it turns out that the most probable structure of C-S-H is given by model 1 . The result of model 4 [33] is also included, the energy calculated on this structure is presented (triangle on Figure 4). 


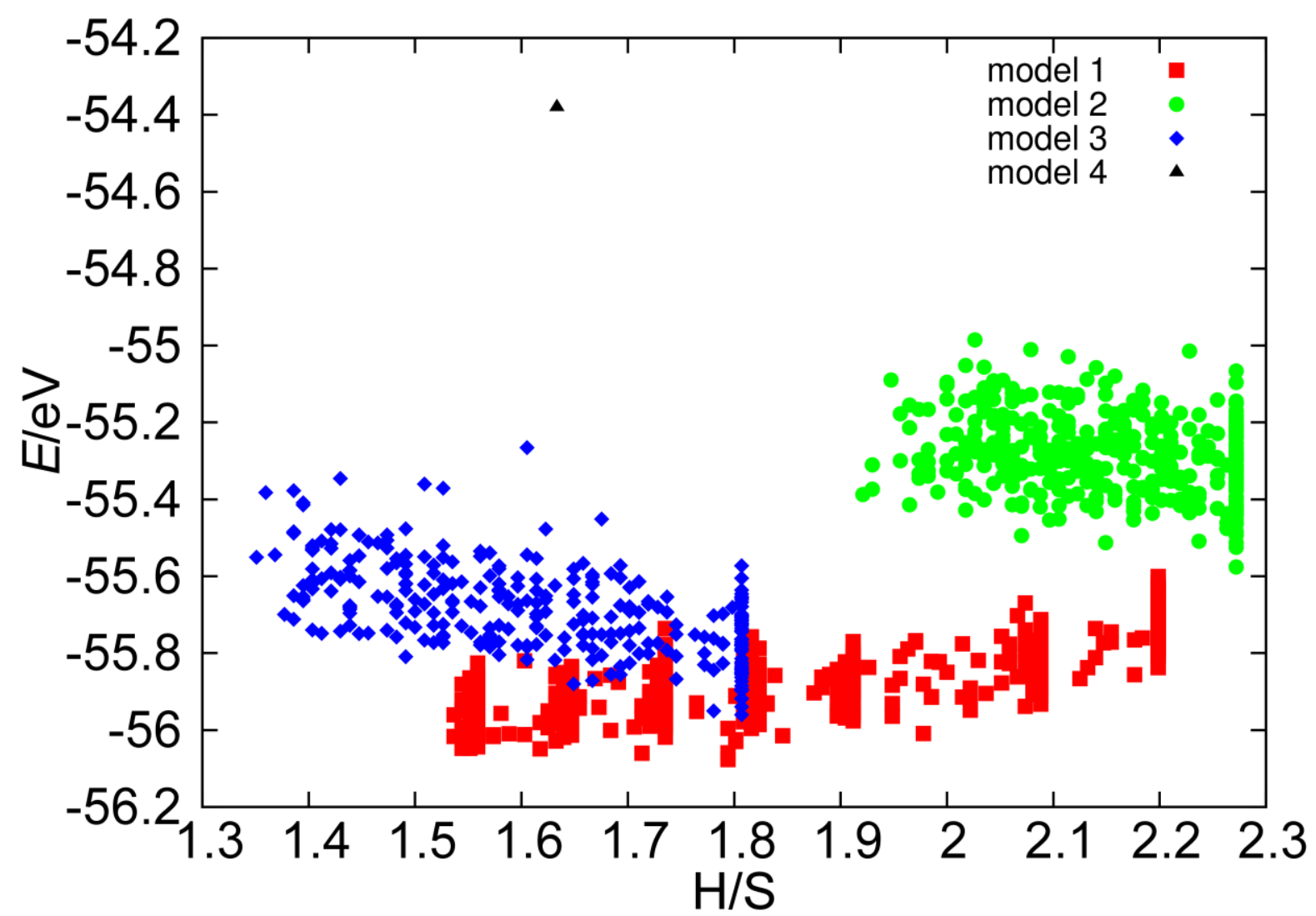

Figure 4: Variation of average energy scaled per silicon atoms (E) of the four C-S-H models according to the water to silicon ratio $(\mathrm{H} / \mathrm{S})$. The $\mathrm{C} / \mathrm{S}$ ratio is the same for all models (1.68).

To verify the predefined assumption about the basic tobermorite structure, we reconstructed Models (1-3) based on Hamid structure of tobermorite [30], with different alignment of silica chains. We did not observe any substantiation change in the total energy for structures based on Hamid and Bonacorsi models. This result is expected, since the layers are separated, and the interaction between them is relatively small.

The most distinctive structural property of these models is the radial distribution of silicon atoms. Other radial distribution functions (RDF) differences other that Si-Si are not representative in this case. $\mathrm{RDF}$ for $\mathrm{Si}-\mathrm{Si}$ in each model are constructed and compared to the 
distance the difference between models 1,2 and 3 is negligible as it can be expected from structurally similar objects. However over a short or middle distance the difference becomes significant enough to discriminate the 3 models.
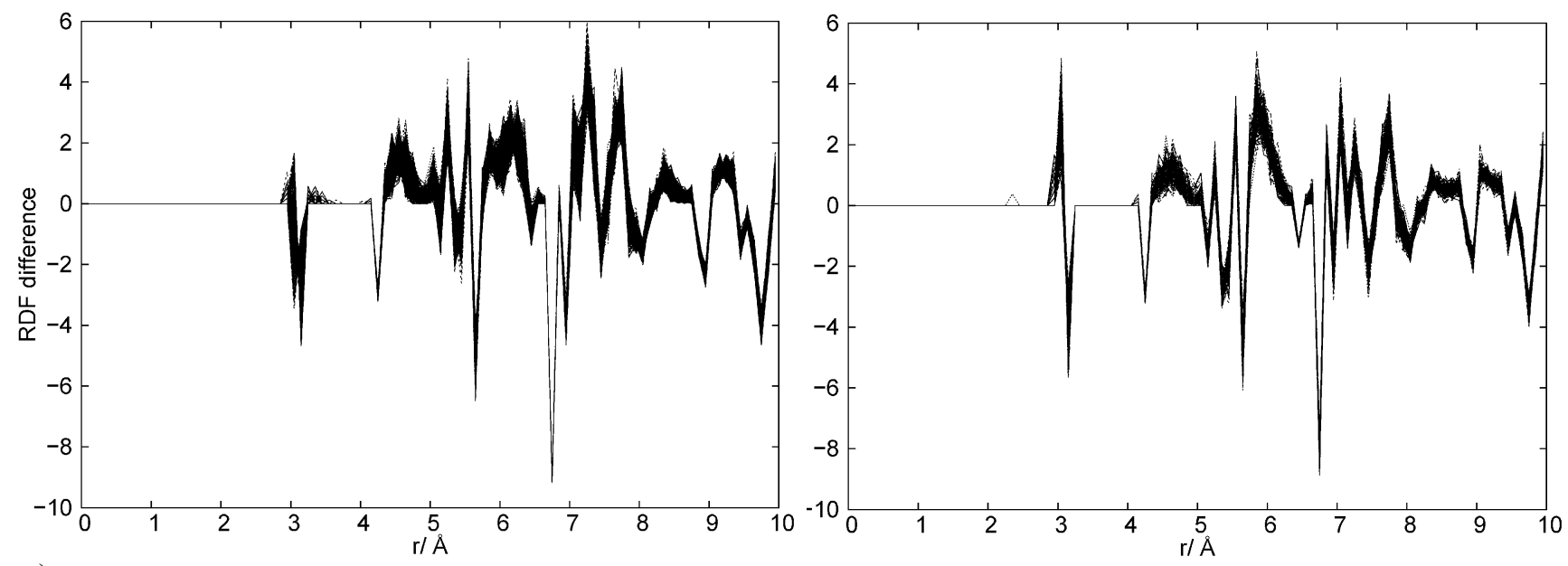

a)

b)

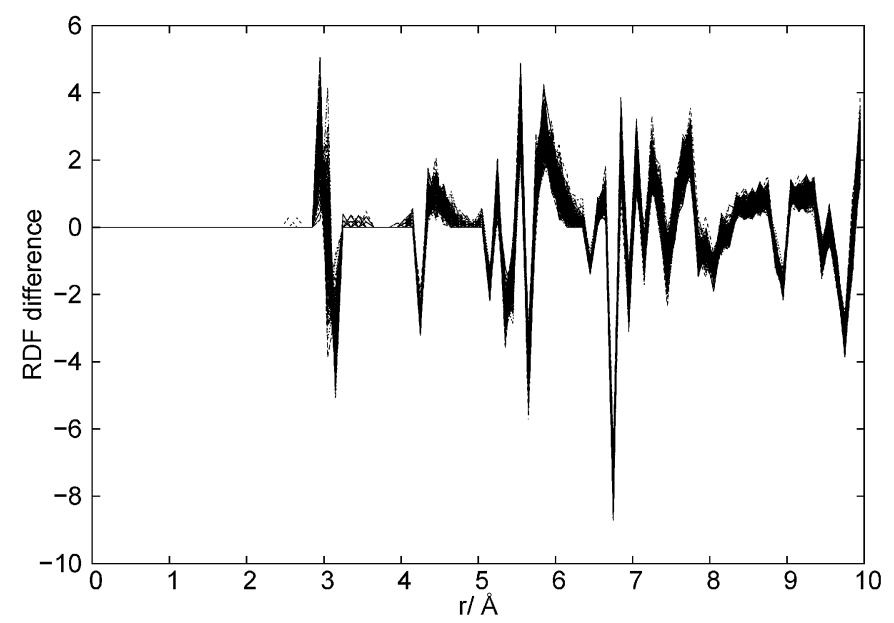

c)

Figure 5: Radial distribution function differences between: a) model 1 and tobermorite, b) model 2 and tobermorite and c) model 3 and tobermorite. Radial distribution functions from many structures within a model are superimposed.

Each model produced structures having slightly different densities according to their water to silicon ratios. These densities are reported in Table 2. Within a model, the variation of the density is almost constant and it does not depend on the water to silicon ratio, yielding three 
models characterized and differentiated by their density. Model 1 shows the density closest to

2 the experimental one [46, 47].

Table 2: Unit cell parameters, average densities $(\rho)$ and corrected densities $\left(\rho_{c}\right)$ of the C-S-H models for different water to silicon ratios $(\mathrm{H} / \mathrm{S})$. Corrected densities are computed for $\mathrm{H} / \mathrm{S} \approx 1.8$ and experimental unit cell volume

\begin{tabular}{|l|l|l|l|l|}
\hline & Model1 & Model 2 & Model 3 & Model 4 \\
\hline $\mathrm{H} / \mathrm{S}$ & $1.55-2.20$ & $2.03-2.27$ & $1.41-1.81$ & 1.63 \\
$a / \AA$ & $30.25-30.83$ & $30.44-30.77$ & $30.08-30.27$ & 26.62 \\
$b / \AA$ & $28.66-29.21$ & $28.84-29.15$ & $27.47-27.64$ & 29.52 \\
$c / \AA$ & $23.38-23.82$ & $23.52-23.77$ & $23.24-23.39$ & 23.69 \\
$\alpha{ }^{\circ}$ & 90.0 & 90.0 & 90.0 & 92.02 \\
$\beta /{ }^{\circ}$ & 90.0 & 90.0 & 90.0 & 88.52 \\
$\gamma /{ }^{\circ}$ & 121.83 & 121.83 & 123.18 & 123.58 \\
$\rho / \mathrm{g} \mathrm{cm}^{-3}$ & $2.39-2.40$ & $2.04-2.07$ & $2.12-2.16$ & 2.34 \\
$\rho_{c} / \mathrm{g} \mathrm{cm}^{-3}$ & 2.76 & 2.44 & 2.32 & 2.37 \\
\hline
\end{tabular}

\section{Discussion}

Model 1 differ from models 2 and 3 in the number of silicate units which were removed from

the ideal tobermorite structure. In model 1, silica monomers were removed, while model 2 is the result of removing four consecutive silica units (including the $\mathrm{Si} 2$ silicates). That led to greater voids between remaining silica oligomers in the structure. The key feature of model 1 and 2 is that they are still composed of dimeric and pentameric $\mathrm{SiO}_{2}$ units. Conversely, the stochastic removal of silicon atoms from the tobermorite structure in model 3 gives a distribution of differently-sized oligomers. Although it was shown by DFT calculations that silicate dimers and pentamers exhibit greatest stability [41]. 
1 Removing a larger number of silica units from model 2 and 3 left these models with a lower 2 density (about $2.15 \mathrm{~g} / \mathrm{cm}^{3}$ ) than model 1 (about $2.42 \mathrm{~g} / \mathrm{cm}^{3}$ ) (table 2). Also, reducing the water 3 content in all models was accomplished by randomly removing the water molecules.

Unfortunately, to the best of our knowledge, there is no experimental crystal density available for such C-S-H at high C/S. However, it can be referred to the experimental evolution of the crystal cell volume according to the $\mathrm{C} / \mathrm{S}$ ratio determined by Renaudin et al. by Rietveld refinement [22]. The corresponding data are reported in figure 6. It is worthwhile to point out that the experimental cell volume do not significantly evolve for $\mathrm{C} / \mathrm{S}$ higher than about 1.1 and is clearly smaller than the ones of the relaxed structures whatever the model (see Table 2).

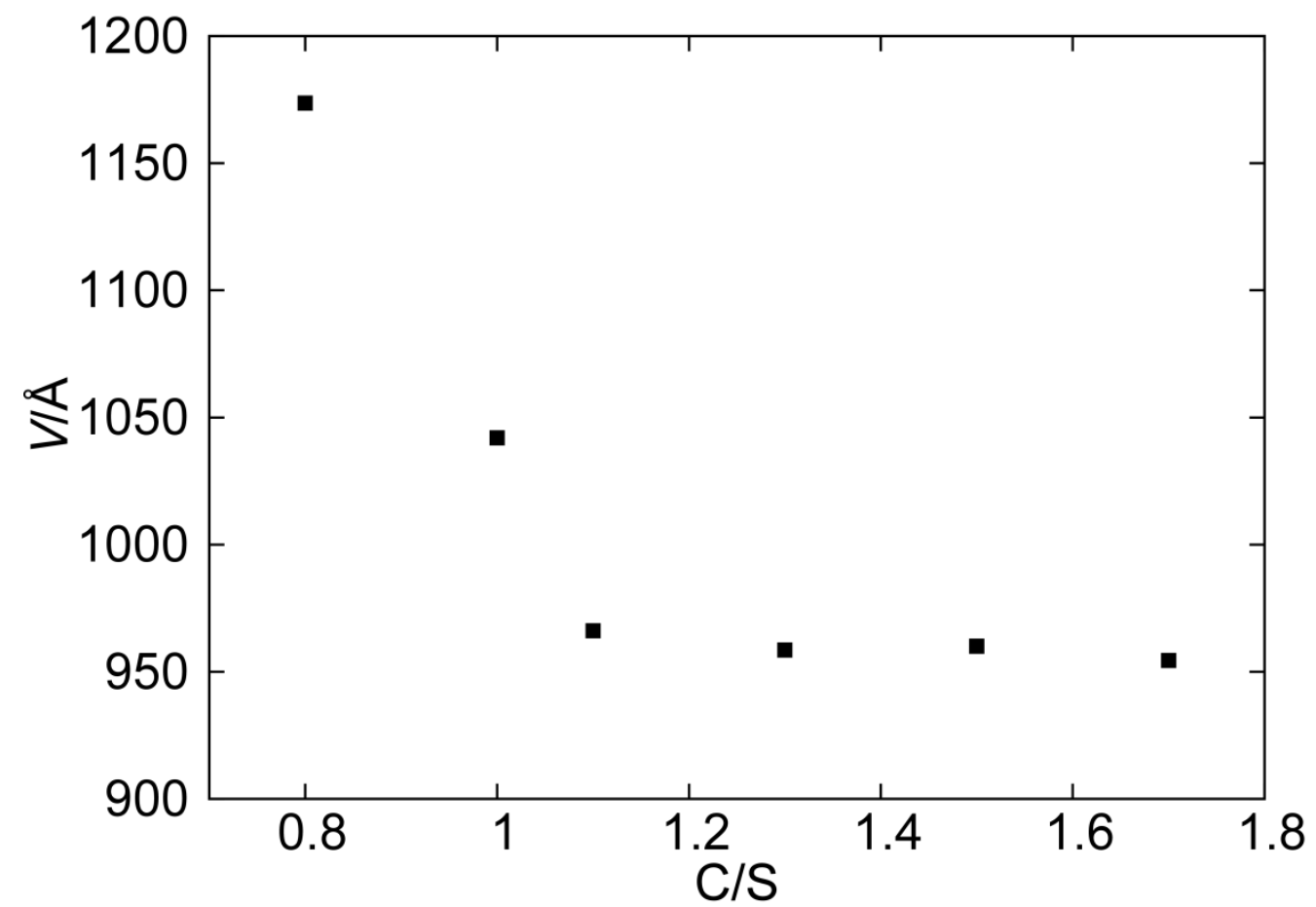

Figure 6: Evolution of the cell volume $(V)$ as a function of the calcium to silicon ratio $(\mathrm{C} / \mathrm{S})$ of C-S-H. Data from Renaudin \& al [22]. 
Computed unit cell sizes differ from experimental ones [22]. The difference can be attributed to overestimation in hydrogen bonds length by ReaxFF [60]. Since the computed unit cell volumes are systematically larger than the experimental unit cell [22], corrected densities are calculated with the experimental unit cell size. This way the calculated densities are the consequence of an internal property characteristic of a model (the crystal cell content) and not due to the computational artifacts. These densities are reported in Table 2 for $\mathrm{H} / \mathrm{S}$ close to 1.8 . In these conditions Model 1 shows the highest density, close to the values determined by different experimental methods. Indeed, at constant $\mathrm{H} / \mathrm{S}$, the variations of densities are directly correlated to the number of calcium and silicon atoms in the cell. Model 1 differs from models 2 and 3 in the number of silicate units which were removed from the ideal tobermorite structure. In model 1, silica monomers were removed, while model 2 is the result of removing four consecutive silica units (including the Si2 silicates). That led to greater voids between remaining silica oligomers in the structure. More calcium atoms are also observed by Renaudin.

The results shown at Figure 4 confirm that model 1 is energetically the most stable of all the models considered. In the same time, all models exhibit some distribution of energy values. Also, the separation between different models is not large especially between 1 and 3, thus the formation of C-S-H may be possible according to model 1 and 3, but the lowest mean energy 


\section{Conclusions}

Three crystal structures of C-S-H, corresponding to three published models, were compared in this study. A set of slightly different structure that belong to these models have been relaxed by geometry optimizations and molecular dynamics simulations. Model 1, has the highest density and the closest to the experimental value, the lowest energy, the narrowest distribution in energies and the greatest degree of order in structure. For these reasons, model 1 is the most suitable. By contrast, being the less stable and showing a density with the largest gap to the experimental value, models 2 and 3 are the less probable.

\section{Acknowledgment}

The authors thank Professor Bo Jönnson for helpful discussions. This research was financed by the BASF Construction Chemicals Division. The computations were performed on resources provided by the Swedish National Infrastructure for Computing (SNIC) at LUNARC

\section{References}

1. Taylor, H.F.W., Cement chemistry. 1997: Academic press. 475.

2. Thomas, J.J., Jennings, H.M., and Allen, A.J., The surface area of cement paste as measured by neutron scattering: evidence for two $\mathrm{C}-\mathrm{S}$-H morphologies. Cem. Concr. Res. 28(6)(1998) 897-905. 
4. $\quad$ Powers, T.C., Structure and physical properties of hardened Portland cement paste. J. Amer. Ceram. Soc. 467. 41(1)(1958) 1-6.

5. Gauffinet, S., Finot, E., Lesniewska, E., and Nonat, A., Direct observation of the growth silicate hydrate on alite and silica surfaces by atomic force microscopy. C.R.Acad. Sc. Earth and Planetary Sciences. 327(1998) 231-236.

6. Nonat, A., The structure and stoichiometry of C-S-H. Cem. Concr. Res. 34(9)(2004) 1521-1528.

7. Taylor, H.F.W., Nanostructure of C-S-H: Current status. Adv. Cem. Based Mater. 1(1993) 38-46.

8. Cong, X. and Kirkpatrick, R.J., 29Si MAS NMR study of the structure of calcium silicate hydrate. Adv. Cem. Based Mater. 3(3-4)(1996) 144-156.

9. Richardson, I.G. and Groves, G.W., A reply to discussions by H.F.W. Taylor of the papers "Models for the composition and structure of calcium silicate hydrate (C-S-H) gel in hardened tricalcium silicate pastes" and "the incorporation of minor and trace elements into calcium silicate hydrate (C-S-H) gel in hardened cement pastes". Cem. Concr. Res. 23(4)(1993) 999-1000.

10. Taylor, H.F.W., Tobermorite, jennite, and cement gel. Z. fur Krist. 202(1992) 41-50.

11. Richardson, I.G., Tobermorite/jennite- and tobermorite/calcium hydroxide-based models for the structure of $C-S-H$ : applicability to hardened pastes of tricalcium silicate, $\beta$-dicalcium silicate, Portland cement, and blends ofportland cement with blast-furnace slag, metakaolin, or silica fume. Cem. Concr. Res. 34(2004) 1733-1777.

12. Lippmaa, E., Gi, M.M., Tarmak, M., Wieker, V., and Grimmer, A.R., A high resolution ${ }^{29} \mathrm{Si}$ NMR study of the hydration of tricalcium silicate. Cem. Concr. Res. 12(1982) 597-602.

13. Damidot, D., Nonat, A., Barret, P., Bertrandie, D., Zanni, H., and Rassem, R., $C_{3} S$ hydration in diluted and stirred suspensions : III NMR study of C-S-H precipited during the two kinetic steps. Adv. Cem. Res. 7(25)(1995) 1-8.

14. Cong, X. and Kirkpatrick, R.J., ${ }^{29}$ Si MAS NMR study of the structure of calcium silicate hydrate. Adv. Cem. Based Mater. 3(1996) 144-156.

15. Cong, X. and Kirkpatrick, R.J., ${ }^{29}$ Si and ${ }^{17} \mathrm{O}$ NMR investigation of the structure of some crystalline calcium silicate hydrates. Adv. Cem. Based Mater. 3(1996) 133-143.

16. Cong, X. and Kirkpatrick, R.J., ${ }^{1} \mathrm{H}-{ }^{29} \mathrm{Si} C P M A S$ NMR study of the structure of calcium silicate hydrate. Adv. Cem. Res. 7(27)(1995) 103-111.

17. Cong, X. and Kirkpatrick, R.J., ${ }^{17} \mathrm{O}$ and ${ }^{29}$ SI MAS NMR study of beta- $C_{2} S$ hydration and the structure of calcium silicate hydrates. Cem. Concr. Res. 23(1993) 1065-1077. 
18. Nonat, A. and Lecoq, X., The structure, stoichiometry and properties of C-S-H prepared by $C_{3} S$ hydration under controlled solution, in Nuclear Magnetic Resonance Spectroscopy of cement based materials, A.G. P. Colombet, H. Zanni, and P. Sozzani, Editor. 1998, Spinger: Berlin. p. 197-207.

19. Renaudin, G., Russias, J., Leroux, F., Cau-dit-Coumes, C., and Frizon, F., Structural characterization of $C-S-H$ and $C$-A-S-H samples-Part II: Local environment investigated by spectroscopic analyses. J. Solid State Chem. 182(12)(2009) 33203329.

20. Klur, I., Pollet, B., Virlet, J., and Nonat, A., C-S-H structure evolution with calcium content by multinuclear NMR, in Nuclear Magnetic Resonance Spectrsoscopy of Cement-Based Materials, A.-R.G. P. Colombet, H. Zanni, P. Sozzani, Editor. 1998, Springer: Berlin. p. 119-141.

21. Brunet, F., Bertani, P., Klur, I., Charpentier, T., Virlet, J., and Nonat, A., Application of ${ }^{29}$ Si homonuclear and ${ }^{1} \mathrm{H} /{ }^{29}$ Si heteronuclear NMR correlation to structural studies of Calcium Silicate Hydrates. J. Phys. Chem. B 108(40)(2004) 15494-15502.

22. Renaudin, G., Russias, J., Leroux, F., Frizon, F., and Cau-Dit-Coumes, C., Structural characterization of $C-S$ - $H$ and $C-A-S-H$ samples-Part I: Long-range order investigated by Rietveld analyses. J. Solid State Chem. 182(12)(2009) 3312-3319.

23. Garbev, K., Beuchle, G., Bornefeld, M., Black, L., and Stemmermann, P., Cell Dimensions and Composition of Nanocrystalline Calcium Silicate Hydrate Solid Solutions. Part 1: Synchrotron-Based X-Ray Diffraction. J. Am. Ceram. Soc. 91(9)(2008) 3005-3014.

24. Garbev, K., Bornefeld, M., Beuchle, G., and Stemmermann, P., Cell Dimensions and Composition of Nanocrystalline Calcium Silicate Hydrate Solid Solutions. Part 2: XRay and Thermogravimetry Study. J. Am. Ceram. Soc. 91(9)(2008) 3015-3023.

25. Soyer-Uzun, S., Chae, S.R., Benmore, C.J., Wenk, H.-R., and Monteiro, P.J.M., Compositional Evolution of Calcium Silicate Hydrate $(C-S-H)$ Structures by Total XRay Scattering. J. Am. Ceram. Soc. 95(2)(2011) 793-798.

26. Viehland, D., Li, J.-F., Yuan, L.-J., and Xu, Z., Mesostructure of calcium silicate hydrate gels in Portland cement paste : short range ordering, nanocrystallinity, and local compositional order. J. Amer. Ceram. Soc. 79(7)(1996) 1731-1744.

27. Richardson, I.G. and Grooves, G.W., Microstructure and microanalysis of hardened ordinary Portland cement pastes. J. Mater. Sci. 28(1993) 265-77.

28. Xu, Z. and Viehland, D., Reply to "Comment on 'Mesostructure of Calcium Silicate Hydrate (C-S-H) Gels in Portland Cement Paste: Short-Range Ordering, Nanocrystallinity, and Local Compositional Order',. J. Am. Ceram. Soc. 80(11)(1997) 2961-2962. 
29. Gard, J.A., Howison, J.W., and Taylor, H.F.W., Synthetic compounds related to tobermorite: an electron-microscope, X-ray, and dehydration study. Mag. Concr. Res. 11(33)(1959) 151-158.

30. Hamid, S.A., The cristal structure of the 11 A natural tobermorite $\mathrm{Ca}_{2.25}\left[\mathrm{Si}_{3} \mathrm{O}_{7.5}(\mathrm{OH})_{1.5}\right] 1 \mathrm{H} 2 \mathrm{O}$. Z. Krist. 15. 154(1981) 189.

31. Nonat, A., Du gâchage à l'état durci, ce sont les mêmes liaisons qui sont à l'oeuvre. Revue française de génie civil. 2(7)(1998) 759-765.

32. Chen, J.J., Thomas, J.J., Taylor, H.F.W., and Jennings, H.M., Solubility and structure of calcium silicate hydrate. Cem. Concr. Res. 34(9)(2004) 1499-1519.

33. Pellenq, R.J.M., Kushima, A., Shahsavari, R., Van Vliet, K.J., Buehler, M.J., Yip, S., and Ulm, F.-J., A realistic molecular model of cement hydrates. Proc. Natl. Acad. Soc. 106(38)(2009) 16102-16107.

34. Richardson, I.G., The calcium silicate hydrates. Cem. Concr. Res. 38(2)(2008) 137158.

35. H.Manzano, J.S.Dolado, A.Ayuela, Elastic properties of the main species present in Portland cement pastes, Acta materialia, 57 (2009) 1666-1674.

36. P.Rejmak, J.S.Dolado, M.J.Stott and A.Ayuela, ${ }^{29}$ SiNMR in cement: a theoretical study on calcium silicate hydrates, J. Phys. Chem. C, 116 (2012) 9755-9761

37. Wieker, W., Grimmer, A.R., Winkler, A., Mägi , M., Tarmak, M., and Lippmaa, E., Solid state high resolution ${ }^{29} \mathrm{Si}$ NMR spectroscopy of synthetic $14 \mathrm{~A}, 11 \mathrm{~A}$ and $9 \mathrm{~A}$ tobermorites. Cem. Concr. Res. 41. 12(1982) 333-339.

38. Kalousek, G.L. and Prebus, A.F., Crystal chemistry of hydrous calcium silicates : III, morphology and other properties of tobermorite and related phases. J. Am. Ceram. Soc. 41(4)(1958) 124-132.

39. Mitsuda, T. and Taylor, H.F.W., Normal and anormalous tobermorites. Mineral. Mag. 42(322)(1978) 229-235.

40. Merlino, S., Bonaccorsi, E., and Armbruster, T., The real structure of tobermorite $11 \mathrm{~A}$...: normal and anomalous forms, OD character and polytypic modifications. Eur. J. Mineral. 13(3)(2001) 577-590.

41. Ayuela, A., Dolado, J.S., Campillo, I., de Miguel, Y.R., Erkizia, E., Sanchez-Portal, D., Rubio, A., Porro, A., and Echenique, P.M., Silicate chain formation in the nanostructure of cement-based materials. J. Chem. Phys. 127(16)(2007) -.

42. Kirkpatrick, R.J., Vibrational spectroscopy of $C-S-H$ and related phases. ACBM, (1997). 
43. Kirkpatrick, R.J., Yarger, J.L., McMillan, P.F., Yu, P., and Cong, X., Raman spectroscopy of C-S-H, Tobermorite, and jennite. Advn. Cem. Bas. Mat. 5(3-4)(1997) 93-99.

44. Cong, X. and Kirkpatrick, R.J., ${ }^{17} \mathrm{O}$ NMR investigation of the structure of the calcium silicate hydrate gel. J. Am. Ceram. Soc. 79( 6)(1996) 1585-1592.

45. Jennings, H.M., Refinements to colloid model of C-S-H in cement: CM-II. Cem. Concr. Res. 38(3)(2008) 275-289.

46. Allen, A.J., Thomas, J.J., and Jennings, H.M., Composition and density of nanoscale calcium-silicate-hydrate in cement. Nat. Mater. 6(4)(2007) 311-316.

47. Muller, A.C.A., Scrivener, K.L., Gajewicz, A.M., and McDonald, P.J., Densification of C-S-H Measured by $1 H$ NMR Relaxometry. J. Phys. Chem. C. 117(1)(2013) 403-412.

48. Bonnaud, P.A., Ji, Q., Coasne, B., Pellenq, R.J.M., and Van Vliet, K.J., Thermodynamics of Water Confined in Porous Calcium-Silicate-Hydrates. Langmuir. 28(31)(2012) 11422-11432.

49. Shahsavari, R., Pellenq, R.J.M., and Ulm, F.-J., Empirical force fields for complex hydrated calcio-silicate layered materials. Phys. Chem. Chem. Phys. 13(3)(2011) 1002-1011.

50. Youssef, M., Pellenq, R.J.M., and Yildiz, B., Glassy Nature of Water in an Ultraconfining Disordered Material: The Case of Calcium Silicate Hydrate. J. Am. Chem. Soc. 133(8)(2011) 2499-2510.

51. Richardson, I., The importance of proper crystal-chemical and geometrical reasoning demonstrated using layered single and double hydroxides, in Acta Cryst. Sect. B. 2013. p. 150-162.

52. Thomas, J.J., Jennings, H.M., and Allen, A.J., Relationships between Composition and Density of Tobermorite, Jennite, and Nanoscale CaO-SiO2-H2O. J. Phys. Chem. C. 114(17)(2010) 7594-7601.

53. Rodger, S.A., Groves, G.W., Clayden, N.J., and Dobson, C.H., Hydration of tricalcium silicate followed by ${ }^{29} \mathrm{Si}$ NMR with cross-polarization. J. Am. Ceram. Soc. 061. 71(2)(1988) 91-96.

54. Jennings, H.M. and Bullard, J.W., From electrons to infrastructure: Engineering concrete from the bottom up. Cem. Concr. Res. 41(7)(2011) 727-735.

55. Ulm, F.-J. and J-M Pellenq, R., Bottom-Up: From Atoms to Concrete Structures, in Damage Mechanics of Cementitious Materials and Structures. 2013, John Wiley \& Sons, Inc. p. 1-18. 
56. Plimpton, S., Fast Parallel Algorithms for Short-Range Molecular Dynamics. J. Comput. Phys. 117(1)(1995) 1-19.

57. van Duin, A.C.T., Strachan, A., Stewman, S., Zhang, Q., Xu, X., and Goddard, W.A., ReaxFFSiO Reactive Force Field for Silicon and Silicon Oxide Systems. J. Phys. Chem. A. 107(19)(2003) 3803-3811.

58. Manzano, H., Masoero, E., Lopez-Arbeloa, I., and Jennings, H.M., Shear deformations in calcium silicate hydrates. Soft Matter. 9(30)(2013) 7333-7341.

59. Fogarty, J.C., Aktulga, H.M., Grama, A.Y., van Duin, A.C.T., and Pandit, S.A., $A$ reactive molecular dynamics simulation of the silica-water interface. J. Chem. Phys. 132(17)(2010) -.

60. Leroch, S. and Wendland, M., Simulation of Forces between Humid Amorphous Silica Surfaces: A Comparison of Empirical Atomistic Force Fields. J. Phys. Chem. C. 116(50)(2012) 26247-26261. 